(1)

CrossMark

\title{
Exercise right heart catheterisation before and after pulmonary endarterectomy in patients with chronic thromboembolic disease
}

\author{
Stefan Guth ${ }^{1,8}$, Christoph B. Wiedenroth ${ }^{1,8}$, Andreas Rieth (10), \\ Manuel J. Richter ${ }^{4}$, Ekkehard Gruenig ${ }^{5}$, Hossein Ardeshir Ghofrani ${ }^{4}$, \\ Matthias Arlt ${ }^{6}$, Christoph Liebetrau ${ }^{2,3,7}$, Diethard Prüfer ${ }^{1}$, Andreas Rolf ${ }^{2,3,7}$, \\ Christian W. Hamm ${ }^{2,3,7}$ and Eckhard Mayer ${ }^{1}$
}

Affiliations: ${ }^{1}$ Dept of Thoracic Surgery, Kerckhoff Heart and Lung Center, Bad Nauheim, Germany. ${ }^{2}$ Dept of Cardiology, Kerckhoff Heart and Lung Center, Bad Nauheim, Germany. ${ }^{3}$ German Centre for Cardiovascular Research (DZHK), Partner Site Rhine-Main, Frankfurt am Main, Germany. ${ }^{4}$ Dept of Pulmonology, Kerckhoff Heart and Lung Center, Bad Nauheim, Germany. ${ }^{5}$ Thorax Clinic, University Hospital Heidelberg, Heidelberg, Germany. ${ }^{6}$ Dept of Anaesthesiology, Kerckhoff Heart and Lung Center, Bad Nauheim, Germany. ${ }^{7}$ Dept of Internal Medicine I, Division of Cardiology and Angiology, Justus Liebig University of Giessen, Giessen, Germany. ${ }^{8}$ These two authors contributed equally to this work.

Correspondence: Stefan Guth, Dept of Thoracic Surgery, Kerckhoff Heart and Lung Center, Benekestrasse 2-8, 61231 Bad Nauheim, Germany. E-mail: s.guthवkerckhoff-klinik.de

@ERSpublications

Pulmonary endarterectomy reduces means of TPR and MPAP/CO slopes to $<3.0$ Wood Units in patients with chronic thromboembolic disease http://ow.ly/Jw4z30lbefW

Cite this article as: Guth S, Wiedenroth $\mathrm{CB}$, Rieth A, et al. Exercise right heart catheterisation before and after pulmonary endarterectomy in patients with chronic thromboembolic disease. Eur Respir J 2018; 52: 1800458 [https://doi.org/10.1183/13993003.00458-2018].

ABSTRACT Symptomatic patients with chronic thromboembolic disease (CTED) without pulmonary hypertension often show an excessive increase in mean pulmonary arterial pressure (MPAP) during exercise.

We report on the impact of pulmonary endarterectomy (PEA) on pulmonary haemodynamics in a prospective series of 32 consecutive CTED patients who underwent PEA. All patients had a comprehensive diagnostic work-up including right heart catheterisation at baseline and 12 months after PEA. Furthermore, in 12 patients exercise right heart catheterisation was performed before and after PEA.

After PEA, MPAP was lower at rest $(20 \pm 3$ versus $17 \pm 3 \mathrm{mmHg} ; \mathrm{p}=0.008)$ and during maximal exercise ( $39 \pm 8$ versus $31 \pm 6 \mathrm{mmHg} ; \mathrm{p}=0.016)$. The mean total pulmonary resistance (TPR) decreased from $3.6 \pm 0.8$ Wood Units (WU) pre-operatively to $2.7 \pm 0.7 \mathrm{WU} 1$ year after PEA $(\mathrm{p}=0.004)$ and the mean slope of the MPAP/cardiac output (CO) relationship decreased from $3.6 \pm 1.0$ to $2.3 \pm 0.8 \mathrm{WU}$ ( $\mathrm{p}=0.002)$. Peak oxygen uptake increased from $1.2 \pm 0.4$ to $1.5 \pm 0.3 \mathrm{~L} \cdot \mathrm{min}^{-1}(\mathrm{p}=0.014)$ and ventilatory equivalents of carbon dioxide decreased from $39 \pm 2$ to $30 \pm 2(\mathrm{p}=0.002)$. There was a significant improvement in quality of life assessed by the Cambridge Pulmonary Hypertension Outcome Review questionnaire.

In CTED patients, PEA resulted in haemodynamic and clinical improvements. The means of TPR and $\mathrm{MPAP} / \mathrm{CO}$ slopes decreased to $<3.0 \mathrm{WU}$. 


\section{Introduction}

Pulmonary endarterectomy (PEA) is the gold standard treatment option for patients with chronic thromboembolic pulmonary hypertension (CTEPH) [1]. In CTEPH patients, fibrotic transformation of pulmonary artery clots associated with secondary microvasculopathy leads to an increase in pulmonary vascular resistance (PVR) [2-4]. Patients with chronic thromboembolic obstructions without pulmonary hypertension (mean pulmonary arterial pressure (MPAP) at rest $<25 \mathrm{mmHg}$ ) are diagnosed with chronic thromboembolic disease (CTED) [5, 6]. These patients have symptoms like dyspnoea upon exertion or fatigue that hamper their daily activities and diminish their quality of life. CTED patients show the same exercise limitations and symptoms as World Health Organization (WHO) Functional Class II or III CTEPH patients as described by DONAHOE et al. [7]. These symptoms are in line with an inadequate response in pulmonary haemodynamics during exercise [8-10]. Successful PEA has been reported in a limited number of patients with CTED without mortality $[9,10]$. The rationale for PEA in operable CTED patients is improvement of their quality of life by improving symptoms and exercise tolerance as reported by TABOADA et al. [9] and van KAN et al. [10]. In addition, with early treatment, potential long-term complications like the development of secondary small-vessel vasculopathy and right heart failure can be avoided $[1,7,11]$. Recently, a report of a multicentre registry of inoperable CTED patients was published that showed improvements in physical capacity and PVR after balloon pulmonary angioplasty, but no exercise data were reported [12].

There is an ongoing discussion about the definition of exercise pulmonary hypertension, which is not reflected by current guidelines [5, 13-15]. Kovacs et al. [16] describe exercise pulmonary hypertension as the presence of resting MPAP $<25 \mathrm{mmHg}$ and MPAP $>30 \mathrm{mmHg}$ during exercise with total pulmonary resistance $(\mathrm{TPR})>3$ Wood Units (WU). In CTED patients the MPAP/cardiac output (CO) slope during exercise is steeper than in healthy subjects [10, 16]. NAEIJE et al. [15] and LEwis et al. [13] have proposed that TPR and MPAP/CO slopes should not exceed 3.0 WU during maximal supine exercise in healthy subjects. The clinical challenge in terms of diagnosis and treatment of exercise pulmonary hypertension was recently summarised [14]. The impairment in circulatory adaptation in CTED patients is also manifested in an increase in dead space ventilation, reduced oxygen pulse and decreased peak oxygen uptake during cardiopulmonary exercise testing (CPET) [10].

Our group reported data on exercise haemodynamics obtained in CTEPH patients before and 1 year after PEA that showed improvement in MPAP/CO slopes after PEA [17]. In CTED patients, PEA has been shown to improve the quality of life (Cambridge Pulmonary Hypertension Outcome Review (CAMPHOR) scores) [9] and reduces MPAP at rest [10]; however, data from exercise right heart catheterisation (RHC) before and after PEA are lacking. We hypothesise that PEA in CTED patients may lead to a decline in TPR and MPAP/CO slopes to $\leqslant 3.0 \mathrm{WU}$ because microvasculopathy probably does not contribute significantly to haemodynamic impairment in this population. Therefore, the aim of the study was to examine parameters of exercise RHC before and after PEA, with a focus on changes in TPR and MPAP/ CO slopes.

\section{Patients and methods \\ Patients}

For this observational study patients with CTED (MPAP $<25 \mathrm{mmHg}$ ) at baseline RHC who underwent PEA between January 1, 2010 and March 31, 2016 were selected from our prospective institutional database. Operability assessment was carried out by a multidisciplinary team consisting of PEA surgeons, (interventional) radiologists, cardiologists and pulmonary physicians. Patients underwent a 6-min walk test, CPET, echocardiography and measurement of $\mathrm{N}$-terminal pro-brain natriuretic peptide levels. Health-related quality of life was measured using the CAMPHOR questionnaire [18]. All patients included underwent PEA according to our institutional protocol [11]. The collection of data was approved by the institutional ethics committee and conducted in keeping with the Declaration of Helsinki (approval AZ 199/15). All patients gave written informed consent.

\section{Right heart catheterisation}

RHC was accomplished by insertion of a Swan-Ganz catheter via the jugular vein under local anaesthesia. Pressure values at rest were assessed continuously and $\mathrm{CO}$ was measured by the thermodilution technique, averaging three out of five output determinations. Baseline parameters were assessed $30 \mathrm{~min}$ after insertion of the catheter. PVR and cardiac index (CI) were calculated as described previously [19]. Exercise was performed on a cycle ergometer in the supine position with a constant external workload of 25, 50 or $75 \mathrm{~W}[20]$.

The zero reference level for the pressure transducer was placed at the mid-thoracic level in the supine position. During exercise, all pulmonary pressures were averaged over several respiratory cycles, which is 
thought to be the most reasonable compromise to compensate for respiratory fluctuations, especially under maximal exercise $[19,21]$. The following haemodynamic parameters were calculated as the main outcome measures: TPG=MPAP-PAWP, DPG=DPAP-PAWP, the slope of the MPAP/CO relationship [13] and $C \mathrm{pa}=(\mathrm{CO} /$ heart rate $) /(\mathrm{SPAP}-\mathrm{DPAP})$, where $\mathrm{TPG}$ is the transpulmonary gradient, PAWP is the pulmonary arterial wedge pressure, DPG is the diastolic pulmonary gradient, $C \mathrm{pa}$ is the pulmonary arterial compliance and SPAP is the systolic pulmonary arterial pressure. Exercise pulmonary hypertension was defined by the presence of resting MPAP $<25 \mathrm{mmHg}$ and MPAP $>30 \mathrm{mmHg}$ at peak exercise while TPR $>3.0 \mathrm{WU}$ as proposed by the European Respiratory Society Task Force [16].

\section{Cardiopulmonary exercise testing}

Patients underwent symptom-limited incremental CPET (MasterScreen, CareFusion; BD, Heidelberg, Germany) according to current recommendations using a ramp protocol with an incremental rate of 5$15 \mathrm{~W} \cdot \mathrm{min}^{-1}$ as judged by the operator [22].

\section{The 6-min walk test}

The 6-min walk test was performed according to current guideline recommendations and results were recorded as the distance covered in metres [23].

\section{Surgical technique}

PEA was performed using the standard technique [24]. Briefly, a median sternotomy was performed and during cardiopulmonary bypass patients were gradually cooled to a core temperature of $20^{\circ} \mathrm{C}$ for safe circulatory arrest $[25,26]$, which was limited to intervals of $20 \mathrm{~min}$.

\section{Statistical analysis}

Continuous variables were tested for adherence to a normal distribution by the D'Agostino-Pearson normality test for normal data and are expressed as mean with standard deviation or as median (interquartile range). Univariate comparisons between patients were performed using the Chi-squared test or Fisher's exact test, where appropriate, for dichotomous variables; the t-test or Mann-Whitney U-test was applied for continuous variables. Statistical tests were two-sided; differences where $\mathrm{p}<0.05$ were considered significant. Prism version 7.03 for Windows (GraphPad, La Jolla, CA, USA) was used for the data and statistical analyses.

\section{Results}

\section{Baseline characteristics}

From January 2010 to March 2016, 664 consecutive symptomatic patients with chronic thromboembolic vascular obstructions underwent PEA surgery at our institution. The in-hospital mortality rate was $3.6 \%$ (24 patients). Within the entire cohort, 32 patients were diagnosed with CTED (defined as MPAP $<25 \mathrm{mmHg}$ at rest). All CTED patients survived the perioperative period.

\section{Results of pre-operative and 1-year post-operative exercise RHC in 12 CTED patients Patient characteristics and baseline noninvasive measurements}

The study flowchart is depicted in figure 1. Baseline characteristics of the 12 CTED patients (median (IQR) age 34 (28-60) years, 50\% females) who underwent exercise RHC are presented in table 1. Results of pulmonary function tests were normal. Eight patients were in WHO Functional Class II and four patients were in WHO Functional Class III. Patients were not on pulmonary hypertension-targeted medication. Nine patients had no perioperative complications. Two patients had minor complications (one urinary tract infection and one atrial fibrillation), and one patient with re-do surgery developed post-operative seizures with suspicion of hypoxic brain damage and needed tracheostomy. Fortunately, this patient had a complete recovery.

\section{Surgical specimens}

All patients had a significant burden of bilateral thromboembolic disease. The endarterectomy specimens as per Jamieson classification were classified as type 1 or 2 disease for the majority of patients $(n=8)$. Specimens from two patients were classified as type 3 disease and for two patients these data were not available.

Exercise RHC before and 1 year after PEA

Exercise RHC data before PEA and 1 year after PEA are depicted in figure 2. Before PEA the slope of the $\mathrm{MPAP} / \mathrm{CO}$ relationship was $>3.0 \mathrm{WU}$ in nine patients (range 1.7-4.9 WU) and TPR was also $>3.0 \mathrm{WU}$ in nine patients who had MPAP $>30 \mathrm{mmHg}$. In one patient TPR was $3.0 \mathrm{WU}$ but MPAP only $29 \mathrm{mmHg}$. At 1 year after PEA, only three patients still fulfilled the criteria of exercise pulmonary hypertension with 


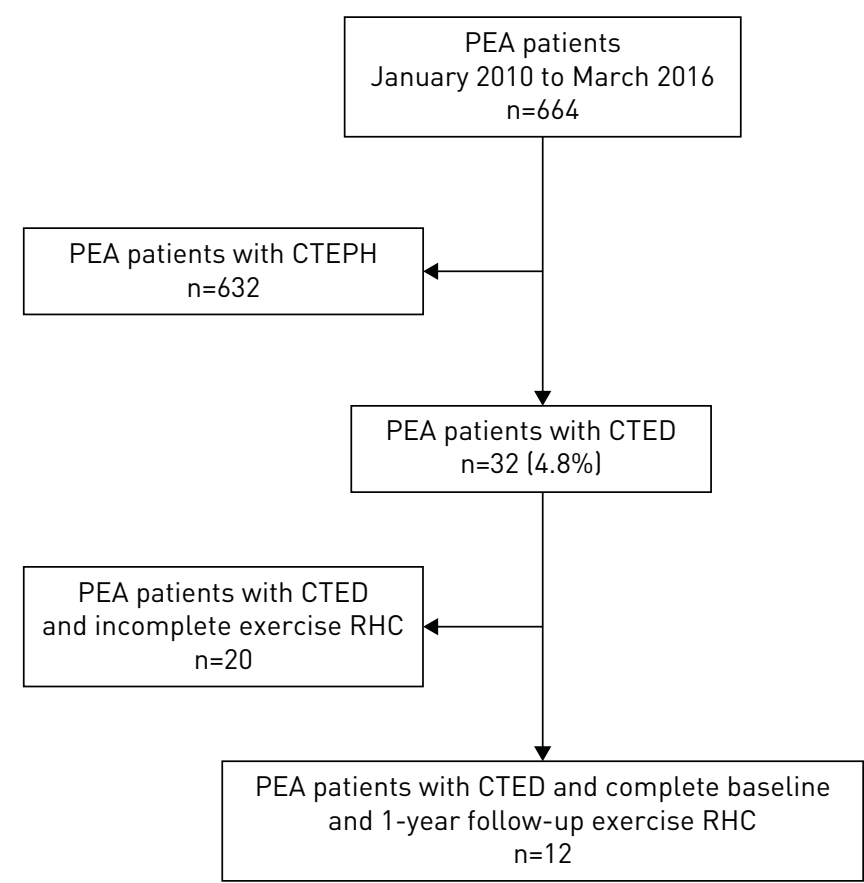

FIGURE 1 Flowchart of patient selection. PEA: pulmonary endarterectomy; CTEPH: chronic thromboembolic pulmonary hypertension; CTED: chronic thromboembolic disease; RHC: right heart catheterisation.

MPAP $>30 \mathrm{mmHg}$ and TPR >3.0 WU. However, after PEA the MPAP/CO slope was <3.0 WU in 11 patients and increased in one patient from 3.5 to $4.3 \mathrm{WU}$. In this patient an excessive rise in PAWP to $25 \mathrm{mmHg}$ was observed, indicating left ventricular diastolic dysfunction. Figure 3 shows the individual changes in TPR and MPAP/CO slope before and after PEA. The mean TPR $(3.6 \pm 0.8$ to $2.7 \pm 0.7 \mathrm{WU}$; $\mathrm{p}=0.0040)$ and mean MPAP/CO slope $(3.6 \pm 1.0$ to $2.3 \pm 0.8 \mathrm{WU} ; \mathrm{p}=0.0024)$ decreased after PEA. Patients with values $>3.0 \mathrm{WU}$ showed a more pronounced decrease, whereas patients with slope values $<3.0 \mathrm{WU}$ showed only a minor decrease.

Haemodynamic responses before and after PEA are summarised in table 2. MPAP at rest showed a reduction from $20 \pm 3$ to $17 \pm 3 \mathrm{mmHg}(\mathrm{p}=0.006)$. Further decreases were observed for SPAP, TPG, PVR and TPR. PAWP showed an increase from $8 \pm 3$ to $11 \pm 4 \mathrm{mmHg}(\mathrm{p}=0.02)$. During exercise RHC pulmonary haemodynamics improved after PEA, whereas CO and CI did not change. Exercise TPG decreased after

\begin{tabular}{|c|c|}
\hline \multicolumn{2}{|c|}{ Baseline characteristics } \\
\hline Age years & $34(24-60)$ \\
\hline \multicolumn{2}{|l|}{ Sex } \\
\hline Male & 6 \\
\hline Female & 6 \\
\hline Height cm & $175 \pm 7$ \\
\hline Weight kg & $81 \pm 17$ \\
\hline $\mathrm{BMI} \mathrm{kg} \cdot \mathrm{m}^{-2}$ & $26.6 \pm 4.9$ \\
\hline \multicolumn{2}{|l|}{ Pulmonary function } \\
\hline FVC L & $3.9 \pm 0.8$ \\
\hline FVC \% pred & $91 \pm 11$ \\
\hline FEV 1 L & $3.1 \pm 0.8$ \\
\hline $\mathrm{FEV}_{1} \%$ pred & $83 \pm 11$ \\
\hline $\mathrm{FEV}_{1} / \mathrm{FVC} \%$ & $78 \pm 6$ \\
\hline TLCO \% pred & $72 \pm 18$ \\
\hline NT-proBNP $n g \cdot L^{-1}$ & $68(25-147)$ \\
\hline
\end{tabular}




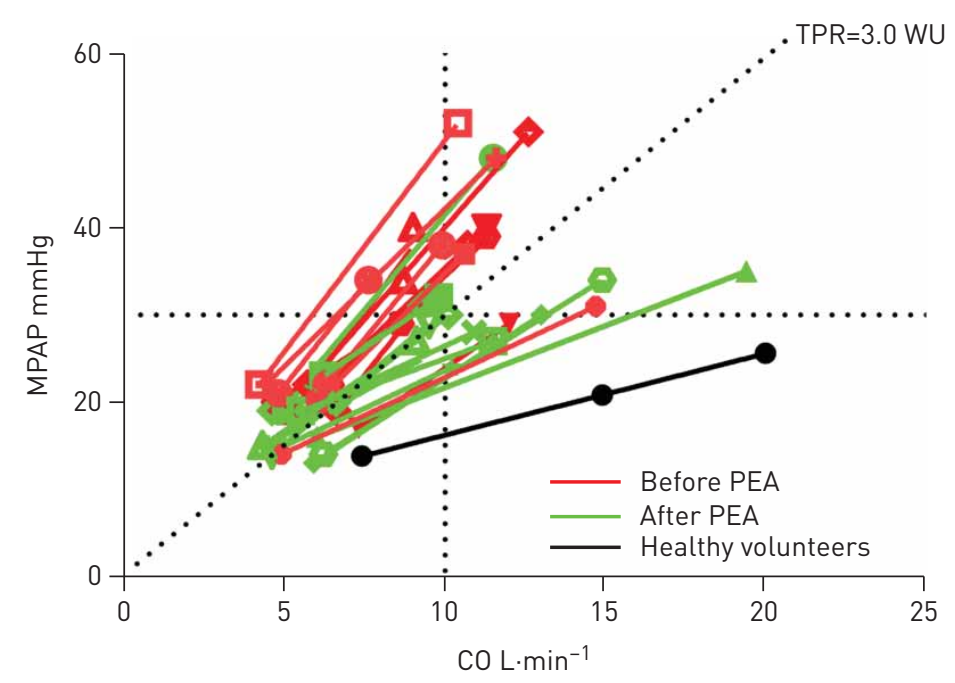

\begin{tabular}{|c|c|}
\hline $\begin{array}{c}\text { Before PEA } \\
\text { WU }\end{array}$ & $\begin{array}{c}\text { After PEA } \\
\text { WU }\end{array}$ \\
\hline 3.7 & 1.4 \\
\hline 4.8 & 2.5 \\
\hline 1.8 & 1.7 \\
\hline 3.6 & 1.7 \\
\hline 4.4 & 1.3 \\
\hline 4.6 & 2.5 \\
\hline 4.2 & 2.9 \\
\hline 4.6 & 2.6 \\
\hline 3.5 & 2.3 \\
\hline 2.3 & 2.0 \\
\hline 3.5 & 4.3 \\
\hline 2.5 & 2.4 \\
\hline
\end{tabular}

FIGURE 2 Mean pulmonary arterial pressure (MPAP)/cardiac output (CO) relationship of 12 patients with exercise right heart catheterisation before and 1 year after pulmonary endarterectomy (PEA). TPR: total pulmonary resistance; WU: Wood Units. The values of the individual slopes are given in the table. The black line shows the mean slope (0.94 WU) of healthy volunteers from Kovacs et al. [27].
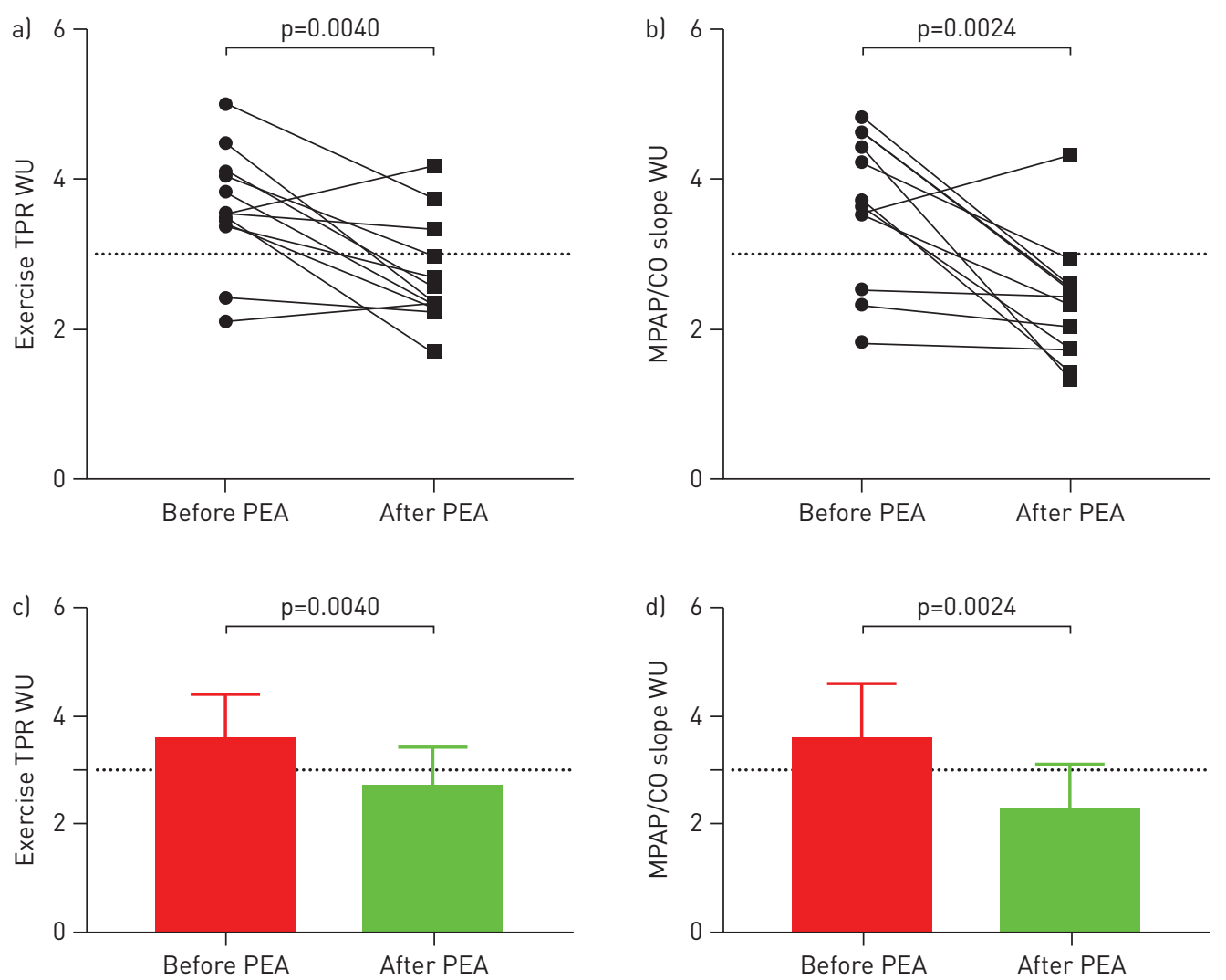

FIGURE $3 a$, b) Individual and $c$, d) mean \pm SD changes in $a, c)$ total pulmonary resistance TPR during exercise and $b, d$ ) slopes of the mean pulmonary arterial pressure (MPAP)/cardiac output (CO) relationship of 12 patients with exercise right heart catheterisation before and 1 year after pulmonary endarterectomy (PEA). WU: Wood Units. The dotted line depicts 3.0 WU, which is the upper limit of normal proposed by NAEIJE et al. [15]. 


\begin{tabular}{|c|c|c|c|}
\hline & Before PEA & After PEA & p-value ${ }^{\#}$ \\
\hline \multicolumn{4}{|l|}{ Rest } \\
\hline SPAP mmHg & $33 \pm 7$ & $29 \pm 5$ & 0.04 \\
\hline MPAP $\mathrm{mmHg}$ & $20 \pm 3$ & $17 \pm 3$ & 0.006 \\
\hline DPAP $\mathrm{mmHg}$ & $10 \pm 3$ & $9 \pm 4$ & 0.4 \\
\hline PAWP $\mathrm{mmHg}$ & $8 \pm 3$ & $11 \pm 4$ & 0.02 \\
\hline RAP $\mathrm{mmHg}$ & $4.3 \pm 2.4$ & $6.5 \pm 3.0$ & 0.1 \\
\hline TPG mmHg & $12 \pm 4$ & $7 \pm 4$ & 0.004 \\
\hline PVR WU & $2.1 \pm 0.9$ & $1.5 \pm 0.5$ & 0.01 \\
\hline $\mathrm{COL} \cdot \mathrm{min}^{-1}$ & $5.6 \pm 1.0$ & $5.6 \pm 0.7$ & 0.9 \\
\hline $\mathrm{Cl} \mathrm{L} \cdot \mathrm{min}^{-1} \cdot \mathrm{m}^{-2}$ & $2.7 \pm 0.3$ & $2.9 \pm 0.5$ & 0.39 \\
\hline$C_{\text {pa }} \mathrm{mL} \cdot \mathrm{mmHg}^{-1}$ & $3.9 \pm 1.6$ & $4.0 \pm 1.0$ & 0.86 \\
\hline $\mathrm{SV} \mathrm{mL} \cdot \mathrm{min}^{-1}$ & $70 \pm 15$ & $77 \pm 12$ & 0.72 \\
\hline Heart rate beats $\cdot \mathrm{min}^{-1}$ & $72 \pm 9$ & $73 \pm 7$ & 0.77 \\
\hline \multicolumn{4}{|l|}{ Maximal exercise } \\
\hline SPAP mmHg & $62 \pm 15$ & $51 \pm 14$ & 0.04 \\
\hline MPAP $\mathrm{mmHg}$ & $39 \pm 8$ & $31 \pm 6$ & 0.02 \\
\hline DPAP mmHg & $19 \pm 5$ & $16 \pm 5$ & 0.05 \\
\hline PAWP $\mathrm{mmHg}$ & $11 \pm 5$ & $11 \pm 4$ & $>0.9$ \\
\hline $\mathrm{TPG} \mathrm{mmHg}$ & $26 \pm 8$ & $18 \pm 6$ & $<0.0001$ \\
\hline PVR WU & $2.7 \pm 1.1$ & $1.8 \pm 1.0$ & 0.001 \\
\hline $\mathrm{CO} L \cdot \mathrm{min}^{-1}$ & $10.9 \pm 1.8$ & $11.6 \pm 3.0$ & 0.52 \\
\hline Exercise pulmonary hypertension & 9 & 3 & 0.04 \\
\hline $\mathrm{Cl} \mathrm{L} \cdot \mathrm{min}^{-1} \cdot \mathrm{m}^{-2}$ & $5.4 \pm 1.6$ & $6.2 \pm 1.8$ & 0.17 \\
\hline$C_{\text {pa }} \mathrm{mL} \cdot \mathrm{mmHg}^{-1}$ & $2.6 \pm 1.1$ & $3.6 \pm 0.8$ & 0.03 \\
\hline $\mathrm{SV} \mathrm{mL} \cdot \mathrm{min}^{-1}$ & $102 \pm 14$ & $113 \pm 29$ & 0.4 \\
\hline Heart rate beats $\cdot \min ^{-1}$ & $106 \pm 23$ & $106 \pm 9$ & $>0.9$ \\
\hline
\end{tabular}

Data presented as mean \pm SD or $n$, unless otherwise stated. SPAP: systolic pulmonary arterial pressure; MPAP: mean pulmonary arterial pressure; DPAP: diastolic pulmonary arterial pressure; PAWP: pulmonary arterial wedge pressure; RAP: right atrial pressure; TPG: transpulmonary pressure gradient; PVR: pulmonary vascular resistance; WU: Wood Units; CO: cardiac output; $\mathrm{Cl}$ : cardiac index; $\mathrm{C}_{\text {pa: }}$ pulmonary arterial compliance; SV: stroke volume. ${ }^{\#}$ : $p<0.05$ considered significant.

1 year for all patients. Interestingly, during exercise the mean $C_{\mathrm{pa}}$ increased from $2.6 \pm 1.1 \mathrm{~mL} \cdot \mathrm{mmHg}^{-1}$ before PEA to $3.6 \pm 0.8 \mathrm{~mL} \cdot \mathrm{mmHg}^{-1}(\mathrm{p}=0.03)$ after PEA.

\section{Noninvasive CPET and quality of life}

CPET parameters and CAMPHOR score outcomes were improved after PEA, as presented in table 3. At 1 year after PEA patients had higher maximal workload, peak oxygen uptake $\left(V^{\prime} \mathrm{O}_{2}\right)$ and peak oxygen pulse compared with baseline values. The ventilatory equivalents of carbon dioxide (minute ventilation $\left.\left(V^{\prime} \mathrm{E}\right) / V^{\prime} \mathrm{CO}_{2}\right)$ at peak exercise decreased without a change in maximal ventilation. In addition, the $V^{\prime} \mathrm{E} / V^{\prime} \mathrm{CO}_{2}$ slope was lower after PEA. PEA improved symptoms in all patients, and all patients returned to WHO Functional Class I and II during the first year after PEA (table 3). The mean values of WHO Functional Class decreased from $2.3 \pm 0.5$ to $1.4 \pm 0.5(\mathrm{p}<0.001)$ (figure 4$)$. We observed improvements in the total CAMPHOR score and in all three domains (i.e. symptoms, activity and quality of life).

\section{Discussion}

The optimal treatment for CTED patients is still a matter of debate $[9,10]$. After pulmonary embolism there is a continuum of symptoms, ranging from patients with "only" detectable perfusion defects $(\sim 30-50 \%)[28,29]$ to very ill patients with severe CTEPH [6, 30-32]. The rationale for offering PEA is that the pathophysiology leading to exercise limitation in CTED is comparable to that in CTEPH. Nevertheless, there are no data available on invasive pre- and post-operative exercise pulmonary haemodynamics. Therefore, the aim of the present study was to determine parameters of exercise RHC before and after PEA, with a focus on changes in TPR and MPAP/CO slopes.

The main findings of the study are: 1) CTED patients showed a decrease in MPAP and exercise TPR 1 year after PEA, 2) the means of TPR and MPAP/CO slopes decreased to $<3.0 \mathrm{WU}$, which is proposed as 
TABLE 3 Noninvasive chronic thromboembolic disease parameters, Cambridge Pulmonary Hypertension Outcome Review (CAMPHOR) scores and 6-min walk distance (6MWD) before and 1 year after pulmonary endarterectomy (PEA)

\begin{tabular}{|c|c|c|c|}
\hline & Before PEA & After PEA & p-value ${ }^{\#}$ \\
\hline \multicolumn{4}{|l|}{ Functional parameters } \\
\hline Maximal workload W & $109 \pm 31$ & $131 \pm 42$ & 0.01 \\
\hline$V^{\prime} \mathrm{O}_{2}$ peak $L \cdot \mathrm{min}^{-1}$ & $1.24 \pm 0.36$ & $1.54 \pm 0.26$ & 0.01 \\
\hline$V^{\prime} \mathrm{O}_{2}$ peak $\%$ pred & $64 \pm 16$ & $81 \pm 22$ & 0.02 \\
\hline Maximal heart rate beats $\cdot \min ^{-1}$ & $142 \pm 23$ & $133 \pm 30$ & 0.13 \\
\hline$V^{\prime} E / V^{\prime} \mathrm{CO}_{2}$ at peak & $39 \pm 2$ & $30 \pm 2$ & 0.002 \\
\hline$V^{\prime} E / V^{\prime} \mathrm{CO}_{2}$ slope & $38 \pm 3$ & $30 \pm 4$ & 0.006 \\
\hline Peak oxygen pulse $\mathrm{mL} \cdot$ beat $^{-1}$ & $10 \pm 2$ & $12 \pm 3$ & 0.02 \\
\hline \multicolumn{4}{|l|}{ CAMPHOR scores } \\
\hline Total score & $23(14-33)$ & $6(2-4)$ & $<0.001$ \\
\hline Symptoms & $8(4-12.5)$ & $2(1-3)$ & 0.001 \\
\hline Activity & $8(4-9.5)$ & $3(0.5-6)$ & 0.001 \\
\hline Quality of life & $7(3.5-12)$ & $2(0.5-3)$ & 0.002 \\
\hline 6MWD m & $437 \pm 105$ & $498 \pm 64$ & 0.2 \\
\hline
\end{tabular}

Data presented as mean \pm SD or median (interquartile range), unless otherwise stated. $V^{\prime} \mathrm{O}_{2}$ : oxygen uptake; $V^{\prime} \mathrm{E}$ : minute ventilation; $V^{\prime} \mathrm{CO}_{2}$ : carbon dioxide production. ${ }^{\#}$ : $\mathrm{p}<0.05$ considered significant.

the upper limit of normal under exercise, and 3) patients showed improved ventilatory efficiency, increased exercise tolerance and improved quality of life.

Recent studies on CTED by TABOADA et al. [9] and by VAN KAN et al. [10] reported the beneficial effect of PEA on CPET parameters, WHO Functional Class, CAMPHOR scores and symptoms. There was a significant improvement in the total score of the CAMPHOR questionnaire from 40 at baseline to 11 at 6 months and this improvement was sustained at 1 year $[9,10]$. MPAP was reduced from $21 \mathrm{mmHg}$ at baseline to $18 \mathrm{mmHg} 6$ months after PEA and PVR decreased from 164 to $128 \mathrm{dyn} \cdot \mathrm{s} \cdot \mathrm{cm}^{-5}$. VAN KAN et al. [10] reported further that 1 year after PEA the oxygen pulse had increased, whereas both peak heart rate and the heart rate response during exercise had decreased. In addition, $V^{\prime} \mathrm{E} / V^{\prime} \mathrm{CO}_{2}$ both at the anaerobic threshold and at peak exercise had decreased, without a concomitant change in maximal ventilation [10]. However, exercise RHC evaluations before and after PEA were not reported in these two publications on CTED.

We were able to demonstrate similar improvements in these values (table 3 ) as well as improvements in exercise pulmonary haemodynamics (table 2) after PEA measured by RHC. Therefore, exercise RHC in CTED patients seems to provide a further diagnostic option in terms of possible treatment decisions.

Furthermore, we found a significant decrease in PVR at rest and during exercise after surgery. In addition, pulmonary arterial compliance, which is considered as an independent predictor of exercise capacity in CTEPH patients, was also improved 1 year after PEA [33]. Along these lines, CLAEssen et al. [34]
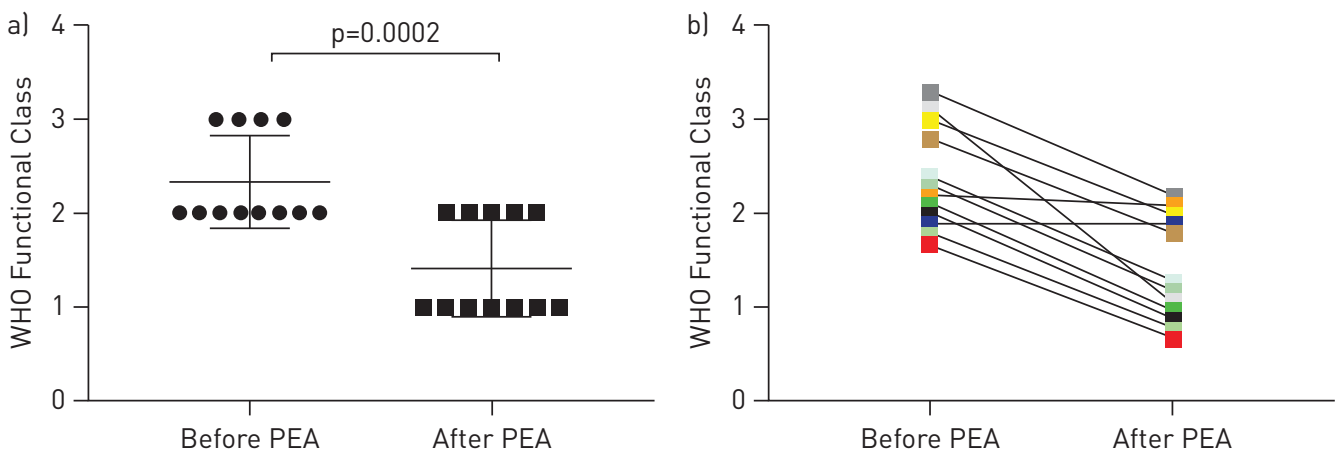

FIGURE 4 Changes in World Health Organization (WHO) Functional Class of 12 patients before and 1 year after pulmonary endarterectomy (PEA). a) Scattered dot plot of the distribution of WHO Functional Class showing mean \pm SD before and after PEA. b) Individual changes in WHO Functional Class before and after PEA. 
emphasised that the MPAP/CO slope and $C_{\mathrm{pa}}$ are sensitive measures of resistive and pulsatile pulmonary vascular function.

These findings highlight the importance of exercise RHC in the diagnosis and treatment of patients with CTED $[13,15,16]$.

\section{Definition of exercise pulmonary hypertension}

CTED patients do not fulfil the definition of pulmonary hypertension. Nevertheless, exercise-based examinations reveal their impaired ability to sufficiently increase their oxygen supply.

From recent data and reflections $[9,13-15,20]$, a reasonable definition of exercise pulmonary hypertension should contain TPR values or MPAP/CO slopes $>3.0 \mathrm{WU}$. Thus, for MPAP $>30 \mathrm{mmHg}, \mathrm{CO}$ should be $<10 \mathrm{~L} \cdot \mathrm{min}^{-1}$. However, there are still several potential confounders (e.g. influence of age, workload, distribution of obstructions and training) that may have an influence. In our study, nine out of 12 patients fulfilled the aforementioned criteria, as they had a TPR and MPAP/CO slope $>3.0$ WU before surgery, and five patients even had slopes $>4.0 \mathrm{WU}$ (figure 2). The mean TPR as well as the mean slope (figure 3) were 3.6 WU, which lies above the proposed upper limit of normal. Interestingly, in all patients but one the slope decreased to $<3.0 \mathrm{WU}$ after PEA, whereas TPR was $>3.0 \mathrm{WU}$ in three patients. Thus, the mean TPR was reduced to $2.7 \mathrm{WU}$ and using the proposed criteria, nine patients had no "exercise pulmonary hypertension" 1 year after surgery. The mean slope 1 year after surgery was significantly reduced to $2.3 \mathrm{WU}$ and 11 patients had a slope $<3.0 \mathrm{WU} 1$ year after surgery.

\section{Cardiopulmonary exercise tests}

In CTEPH, as in pulmonary arterial hypertension, ZHAI et al. [35] demonstrated that the ventilatory efficiency is impaired and highlighted that for CTEPH there was no correlation to the functional classes; however, no CTED patients were included in their report. Donahoe et al. [7] demonstrated increased ventilatory equivalents for carbon dioxide at anaerobic threshold and peak exercise similar to the results for our patients, but no post-operative data exist. One case report of CTED described improvements in right ventricular performance and ventilatory efficiency following PEA, but no exercise RHC data were mentioned [36]. Recently, it was shown by HeLD et al. [37] that CPET is a valuable diagnostic tool for the detection of CTED/CTEPH in patients with suspected pulmonary hypertension but normal echocardiography, and that individual CPET parameters can help to distinguish between CTEPH patients and controls. Our results of CPET (table 3 ) are in line with the improved haemodynamic response obtained from exercise RHC. At 1 year after PEA, patients significantly increased their maximal workload, peak oxygen uptake and peak oxygen pulse. VAN KAN et al. [10] also reported CPET data from CTED patients but did not observe significant differences before and after PEA. However, they stated that $V^{\prime} \mathrm{E} / V^{\prime} \mathrm{CO}_{2}$ at peak and at the anaerobic threshold as well as the $V^{\prime} \mathrm{E} / V^{\prime} \mathrm{CO}_{2}$ slope significantly decreased 1 year after PEA. We observed the same significant decreases in ventilatory equivalents and $V^{\prime} \mathrm{E} / V^{\prime} \mathrm{CO}_{2}$ slopes after PEA, which were restored to normal or at least near-normal values.

This improvement in quality of life and exercise tolerance is further demonstrated in marked decreases in scores in all CAMPHOR subcategories. However, since the long-term survival of CTED patients might be excellent without PEA, the indication for surgery in these patients must be assessed individually, and must take into account their expectations and acceptance of risk [38].

\section{Relevance of exercise RHC}

Our data confirm the clinical relevance of the assessment of pulmonary haemodynamics during exercise and are in line with the new concept of exercise pulmonary hypertension. There was an improvement in haemodynamics after PEA and there was no excessive rise in MPAP during exercise except for one patient with a high PAWP.

Since our data show that 1 year after surgery the means of TPR and MPAP/CO slopes decreased to $<3.0 \mathrm{WU}$ within CTED patients, the new definition of exercise pulmonary hypertension seems meaningful and should be applied. Recently, Kovacs et al. [20] reported exercise data from a study including 141 patients of whom 32 had borderline PAP elevation (MPAP 21-24 mmHg). The reasons for applying RHC were exertional dyspnoea that could not be explained by heart or lung disease, or suspected pulmonary hypertension due to pulmonary hypertension-associated diseases such as collagen vascular disease or myelodysplastic syndrome. Kovacs et al. [20] showed that during exercise, the MPAP/CO slope in patients with borderline pulmonary hypertension was significantly steeper $(5.2 \mathrm{WU})$ than in patients with resting MPAP $<21 \mathrm{mmHg}$ (3.2 WU). This was accompanied by a higher mortality in the borderline group. DONAHOE et al. [7] reported one of 22 CTED patients with progression to CTEPH requiring lung transplantation, suggesting a realistic risk of worsening. However, larger studies providing evidence for the prognostic relevance of exercise pulmonary hypertension in CTED are needed. 


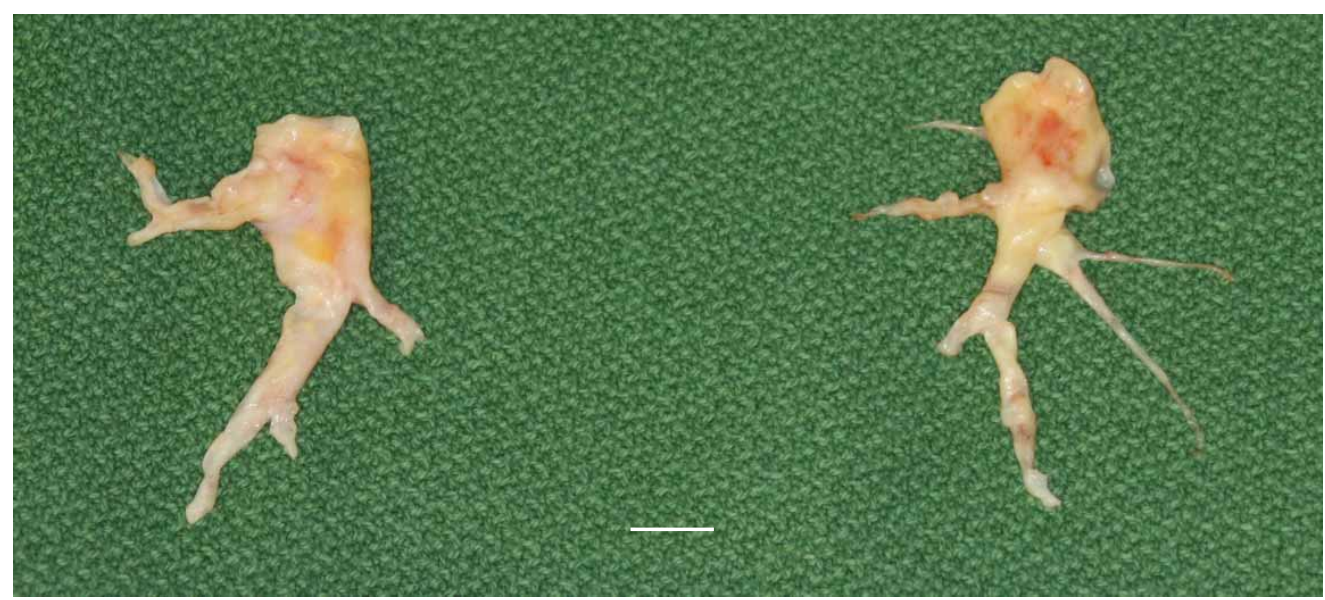

FIGURE 5 Pulmonary endarterectomy specimens of a patient with chronic thromboembolic disease. Scale bar: $1 \mathrm{~cm}$

\section{Limitations}

There are several limitations of the present study. The number of patients included was low, there was no comparative cohort of patients with CTED who were treated conservatively and RHC was performed at only two time-points. A major concern that should also be noted is the fact that we offer a complex operation to patients who experience symptoms only during exercise. Even when PEA is performed at an expert centre [1,32], there remains a considerable perioperative risk and it is debatable whether surgery should be offered to these patients. However, given their significant symptoms in the context of an abnormal haemodynamic response during exercise, we offered surgery because these patients complain about their unacceptable quality of life. The post-operative course was uneventful in all patients but one, who developed seizures in the early post-operative phase after re-do surgery. Fortunately, the patient completely recovered after a prolonged hospital stay. However, all patients who had complained about their daily physical shortcomings showed significantly improved physiological responses upon exercise after PEA, which translated to a better or normalised quality of life. Therefore, in carefully selected patients with symptomatic CTED, treatment by PEA appears to be a reasonable option, but should only be performed at expert centres (figure 5) [39].

\section{Conclusions}

Patients with CTED showed an excessive rise in MPAP and steep slopes of the MPAP/CO relationship during exercise RHC in combination with poor performance in CPET. The mean values of TPR and MPAP/CO slopes were $>3.0 \mathrm{WU}$, but after successful PEA surgery the haemodynamic response improved significantly, and the means of TPR and MPAP/CO slopes were 2.7 and $2.3 \mathrm{WU}$, respectively, which is clearly below the proposed upper limit of normal. These results were accompanied by better exercise tolerance and quality of life.

Acknowledgements: The authors thank Elizabeth Martinson (Franz Groedel Institute, Bad Nauheim, Germany) for critical language editing of the manuscript.

Conflict of interest: S. Guth reports nonfinancial support from the German Center for Lung Research, during the conduct of the study; personal fees from Actelion Pharmaceuticals, Bayer, Pfizer and GSK, outside the submitted work. C.B. Wiedenroth reports nonfinancial support from the German Center for Lung Research, during the conduct of the study; personal fees from Actelion, Bayer AG, BTG, MSD and Pfizer, outside the submitted work. A. Rieth reports nonfinancial support from the German Center for Lung Research, during the conduct of the study; personal fees from Actelion Pharmaceuticals, Novartis, Servier and St Jude Medical, and grants from Pfizer, outside the submitted work. M.J. Richter reports nonfinancial support from the German Center for Lung Research, during the conduct of the study; personal fees and nonfinancial support from Actelion Pharmaceuticals, personal fees from Bayer, Mundipharma, OMT and Roche, outside the submitted work. H.A. Ghofrani reports nonfinancial support from the German Center for Lung Research, during the conduct of the study; grants and personal fees from Actelion Pharmaceuticals, Bayer, Pfizer and Novartis, personal fees from Bellerophon Pulse Technologies, Medscape, OMT, UCB Celltech, WebMD Global, Gilead Sciences, GSK and Merck, outside the submitted work. C. Liebetrau reports nonfinancial support from the German Center for Lung Research, during the conduct of the study; personal fees from Abbott, Bayer, Pfizer, AstraZeneca, Berlin-Chemie, Boehringer Ingelheim, Daiichi Sankyo and Elixir Medical, outside the submitted work. A. Rolf reports personal fees from AstraZeneca, Boehringer Ingelheim and Pfizer-Bristol-Myers Squibb, outside the submitted work. C.W. Hamm reports nonfinancial support from the German Center for Lung Research, during the conduct of the study. E. Mayer reports nonfinancial support from the German Center for Lung Research, during the conduct of the study; 
personal fees from Actelion Pharmaceuticals, Bayer, Pfizer, GSK and MSD, outside the submitted work. E. Gruenig has received fees for lectures and/or consultations from Actelion Pharmaceuticals, Bayer/MSD, GSK, United Therapeutics and Pfizer

\section{References}

1 Madani MM, Auger WR, Pretorius V, et al. Pulmonary endarterectomy: recent changes in a single institution's experience of more than 2,700 patients. Ann Thorac Surg 2012; 94: 97-103.

2 Galie N, Humbert M, Vachiery JL, et al. 2015 ESC/ERS Guidelines for the diagnosis and treatment of pulmonary hypertension: The Joint Task Force for the Diagnosis and Treatment of Pulmonary Hypertension of the European Society of Cardiology (ESC) and the European Respiratory Society (ERS): Endorsed by: Association for European Paediatric and Congenital Cardiology (AEPC), International Society for Heart and Lung Transplantation (ISHLT). Eur Heart J 2016; 37: 67-119.

3 Lang IM, Pesavento R, Bonderman D, et al. Risk factors and basic mechanisms of chronic thromboembolic pulmonary hypertension: a current understanding. Eur Respir J 2013; 41: 462-468.

4 Kim NH, Delcroix M, Jenkins DP, et al. Chronic thromboembolic pulmonary hypertension. J Am Coll Cardiol 2013; 62: D92-D99.

5 Hoeper MM, Bogaard HJ, Condliffe R, et al. Definitions and diagnosis of pulmonary hypertension. J Am Coll Cardiol 2013; 62: D42-D50.

6 Sista AK, Klok FA. Late outcomes of pulmonary embolism: the post-PE syndrome. Thromb Res 2018; 164: 157-162.

7 Donahoe L, Vanderlaan R, Thenganatt J, et al. Symptoms are more useful than echocardiography in patient selection for pulmonary endarterectomy. Ann Thorac Surg 2017; 104: 1179-1185.

8 Held M, Kolb P, Grun M, et al. Functional characterization of patients with chronic thromboembolic disease Respiration 2016; 91: 503-509.

9 Taboada D, Pepke-Zaba J, Jenkins DP, et al. Outcome of pulmonary endarterectomy in symptomatic chronic thromboembolic disease. Eur Respir J 2014; 44: 1635-1645.

10 van Kan C, van der Plas MN, Reesink HJ, et al. Hemodynamic and ventilatory responses during exercise in chronic thromboembolic disease. J Thorac Cardiovasc Surg 2016; 152: 763-771.

11 Mayer E. Surgical and post-operative treatment of chronic thromboembolic pulmonary hypertension. Eur Respir Rev 2010; 19: 64-67.

12 Wiedenroth $\mathrm{CB}$, Olsson $\mathrm{KM}$, Guth S, et al. Balloon pulmonary angioplasty for inoperable patients with chronic thromboembolic disease. Pulm Circ 2018; 8: 2045893217753122.

13 Lewis GD, Bossone E, Naeije R, et al. Pulmonary vascular hemodynamic response to exercise in cardiopulmonary diseases. Circulation 2013; 128: 1470-1479.

14 Naeije R, Saggar R, Badesch D, et al. Exercise-induced pulmonary hypertension: translating pathophysiological concepts into clinical practice. Chest 2018; 154: 10-15.

15 Naeije R, Vanderpool R, Dhakal BP, et al. Exercise-induced pulmonary hypertension: physiological basis and methodological concerns. Am J Respir Crit Care Med 2013; 187: 576-583.

16 Kovacs G, Herve P, Barbera JA, et al. An official European Respiratory Society statement: pulmonary haemodynamics during exercise. Eur Respir J 2017; 50: 1700578.

17 Richter MJ, Sommer N, Gall H, et al. Pulmonary hemodynamic response to exercise in chronic thromboembolic pulmonary hypertension before and after pulmonary endarterectomy. Respiration 2015; 90: 63-73.

18 McKenna SP, Doughty N, Meads DM, et al. The Cambridge Pulmonary Hypertension Outcome Review (CAMPHOR): a measure of health-related quality of life and quality of life for patients with pulmonary hypertension. Qual Life Res 2006; 15: 103-115.

19 Rieth A, Richter MJ, Gall H, et al. Hemodynamic phenotyping based on exercise catheterization predicts outcome in patients with heart failure and reduced ejection fraction. J Heart Lung Transplant 2017; 36: 880-889.

20 Kovacs G, Avian A, Tscherner M, et al. Characterization of patients with borderline pulmonary arterial pressure. Chest 2014; 146: 1486-1493.

21 Kovacs G, Avian A, Pienn M, et al. Reading pulmonary vascular pressure tracings. How to handle the problems of zero leveling and respiratory swings. Am J Respir Crit Care Med 2014; 190: 252-257.

22 Balady GJ, Arena R, Sietsema K, et al. Clinician's Guide to cardiopulmonary exercise testing in adults: a scientific statement from the American Heart Association. Circulation 2010; 122: 191-225.

23 ATS Committee on Proficiency Standards for Clinical Pulmonary Function Laboratories. ATS statement: guidelines for the six-minute walk test. Am J Respir Crit Care Med 2002; 166: 111-117.

24 Jamieson SW. Pulmonary thromboendarterectomy. Heart 1998; 79: 118-120.

25 Jamieson SW, Kapelanski DP. Pulmonary endarterectomy. Curr Probl Surg 2000; 37: 165-252.

26 Madani MM, Jamieson SW. Technical advances of pulmonary endarterectomy for chronic thromboembolic pulmonary hypertension. Semin Thorac Cardiovasc Surg 2006; 18: 243-249.

27 Kovacs G, Berghold A, Scheidl S, et al. Pulmonary arterial pressure during rest and exercise in healthy subjects: a systematic review. Eur Respir J 2009; 34: 888-894.

28 Nijkeuter M, Hovens MM, Davidson BL, et al. Resolution of thromboemboli in patients with acute pulmonary embolism: a systematic review. Chest 2006; 129: 192-197.

29 Sanchez O, Helley D, Couchon S, et al. Perfusion defects after pulmonary embolism: risk factors and clinical significance. J Thromb Haemost 2010; 8: 1248-1255.

30 Klok FA, van der Hulle T, den Exter PL, et al. The post-PE syndrome: a new concept for chronic complications of pulmonary embolism. Blood Rev 2014; 28: 221-226.

31 Lankeit M, Krieg V, Hobohm L, et al. Pulmonary endarterectomy in chronic thromboembolic pulmonary hypertension. J Heart Lung Transplant 2017; 37: 250-258.

32 Mayer E, Jenkins D, Lindner J, et al. Surgical management and outcome of patients with chronic thromboembolic pulmonary hypertension: results from an international prospective registry. J Thorac Cardiovasc Surg 2011; 141: 702-710.

33 Bonderman D, Martischnig AM, Vonbank K, et al. Right ventricular load at exercise is a cause of persistent exercise limitation in patients with normal resting pulmonary vascular resistance after pulmonary endarterectomy. Chest 2011; 139: 122-127. 
34 Claessen G, La Gerche A, Dymarkowski S, et al. Pulmonary vascular and right ventricular reserve in patients with normalized resting hemodynamics after pulmonary endarterectomy. J Am Heart Assoc 2015; 4: e001602.

35 Zhai Z, Murphy K, Tighe H, et al. Differences in ventilatory inefficiency between pulmonary arterial hypertension and chronic thromboembolic pulmonary hypertension. Chest 2011; 140: 1284-1291.

36 McCabe C, Preston SD, Gopalan D, et al. Cardiopulmonary exercise testing suggests a beneficial response to pulmonary endarterectomy in a patient with chronic thromboembolic obstruction and normal preoperative pulmonary hemodynamics. Pulm Circ 2014; 4: 137-141.

37 Held M, Grun M, Holl R, et al. Cardiopulmonary exercise testing to detect chronic thromboembolic pulmonary hypertension in patients with normal echocardiography. Respiration 2014; 87: 379-387.

38 de Perrot M, Mayer E. Chronic thromboembolic pulmonary hypertension: do we need a new definition? Eur Respir J 2014; 44: 1401-1403.

39 Jenkins DP, Biederman A, D'Armini AM, et al. Operability assessment in CTEPH: lessons from the CHEST-1 study. J Thorac Cardiovasc Surg 2016; 152: 669-674. 